\title{
Serological Assessment of Rubella During Pregnancy
}

\author{
J. E. BANATVALA, ${ }^{*}$ M.D., M.R.C.PATH., D.P.H. ; JENNIFER M. BEST, $†$ PH.D., B.SC. ; J. BERTRAND, $\ddagger$ F.I.M.L.T. \\ NARELLE A. BOWERN, $\llbracket$; SHEILA M. HUDSON, $\|$ B.SC.
}

British Medical fournal, 1970, 3, 247-250

\begin{abstract}
Cummary: In 45 patients with rubella-like illnesses dur$\checkmark$ ing pregnancy serological tests showed that the clinical diagnosis had been accurate in only 20. Since only 16 of these patients had presented for laboratory investigations within a week of the onset of symptoms, the value of haemagglutination-inhibition tests was considerably reduced; the diagnosis in these cases was confirmed by complement-fixation and rubella-specific IgM tests.

Of 172 patients exposed to a rubella-like illness, only 17 were seronegative; 105 sought advice within two weeks of exposure, and therefore the haemagglutination-inhibition antibody tests were useful in determining immunity. Since the clinical diagnosis of rubella was proved incorrect in a number of cases, these pregnancies were saved. Hence both doctors and patients should report both exposure to and rubella-like illnesses as early as possible, so that laboratory investigations may be carried out without delay.
\end{abstract}

\section{Introduction}

Prospective inquiries have shown that 15 to $35 \%$ of infants born to mothers who have had rubella-like illnesses in early pregnancy may have one or more congenital malformations (Lundström, 1952, 1962; Bradford Hill et al., 1958; Manson et al., 1960; Sheridan, 1964; Pitt and Keir, 1965). Shortly after techniques for laboratory diagnosis became available it was realized that a clinical diagnosis was often incorrect, since a typical rubella-like illness oould be caused by viruses other than rubella-for example, certain enteroviruses-and also because it could present atypically or even without any symptoms. As most prospective inquiries were conducted before laboratory techniques for diagnosis were available many patients who did not have rubella were probably included; the incidence of deformities due to rubella may therefore have been underestimated. Moreover, since clinical diagnosis is unreliable, it is important that patients who are exposed to or who develop rubella-like illnesses in early pregnancy be investigated virologically whenever possible. Both the improvement of established techniques and the development of new ones now make it possible for the laboratory to help clinicians assess most patients.

Below we describe our experience in assessing patients who were either exposed to or who developed rubella-like illnesses during pregnancy between July 1966 and February 1970. We have also tried to determine the value and limitations of the investigations that were carried out.

\section{Patients and Methods}

Patients were referred for investigation by the obstetric departments of St. Thomas's, the Lambeth, and the General Lying-In Hospitals and the Royal Postgraduate Medical School. Occasionally, patients were referred direct by general practitioners and a few specimens were sent-particularly for density gradient studies-by some public health laboratories and other hospitals.

* Consultant Virologist and Senior Lecturer.

$\dagger$ Honorary Lecturer.

$\ddagger$ Senior Tech
Technician.

If Research Assistant.

Research Assistant.
Department of Clinical Virology, St. Thomas's Hospital and Medical School, L.ondon S.E.1.

\section{Virological Investigations}

After Rubella-like Illnesses.-The first serum sample was $\stackrel{\mathbb{\Omega}}{\Omega}$ obtained as soon as possible after the development of a rubella-like illness, a second sample being taken 7 to $10 \stackrel{\mathrm{s}}{\rightarrow}$ days later. Sera were tested in parallel by haemagglutination-inhibition and complement-fixation tests. If there was $\vec{\omega}$ no significant increase in antibody titre, particularly if the $\stackrel{\circ}{\circ}$ first serum sample was obtained a week or more after onset, this sample was examined for the presence of rubella- $\frac{3}{\omega}$. specific IgM to determine whether the haemagglutination- of inhibition antibodies resulted from recent infection. This test was also carried out when only a single serum specimen was iv available and a decision on whether pregnancy should be terminated was required urgently.

After Exposure to Rubella.-A serum sample was obtained from each patient as soon as possible after she had been $\rightarrow$ exposed to a rubella-like illness. Where possible, particularly if exposure had occurred within the family group, serum क्? was also obtained from the index case to determine whether $\overrightarrow{\vec{\theta}}$ the illness was indeed rubella. Similarly, when the interval between first exposure and collection of blood was short-for example, 14 days or less-and despite the presence of haemagglutination-inhibition antibody suggesting that the patient was already immune, an additional serum :ample was taken 7 to 10 days later. This was done lest both index case and the patient were exposed to a common source of infec- $\unrhd$ tion, the patient experiencing an inapparent infection and her $\overrightarrow{\overrightarrow{0}}$ contact the clinically recognizable one. All sera were tested 3 by haemagglutination-inhibition and complement-fixation tests to detect significant rises ( $>$ fourfold) in antibody titre. If the patient was found to be seronegative, additional serum samples were taken about three weeks after the first exposure and then at weekly intervals for three weeks to determine by haemagglutination-inhibition and complement-fixation tests whether seroconversion had taken place. In calculating the approximate date of first exposure it was important to bear in mind that patients may shed virus for a week or more before $ᄋ$ the onset of the illness.

\section{Haemagglutination-inhibition Tests}

These tests were originally conducted according to the $N$ method described by Stewart et al. (1967), serum samples being pretreated with kaolin to remove non-specific inhibitors. After January 1968 all sera were pretreated with $\stackrel{\varrho}{工}$ heparin and manganous chloride, since this method provides a more reliable method of removing serum inhibitors (Feldman, 1968; Plotkin et al., 1968; Cooper et al., 1969). Eight units of ether-Tween split rubella virus antigen (Judith) and $0.25 \%$ of day-old chick cells were used in these tests.

\section{Complement-fixation Tests}

Originally, complement-fixation tests were carried out by means of an alkaline-extracted antigen (Halonen et al., $\stackrel{\vec{P}}{\overrightarrow{+}}$ 1967), but after June 1968 a mixture of an alkaline and a sonically extracted antigen obtained from the Central Public Health Laboratory, Colindale, was used. Tests were conducted with 2.5 units of complement and antigen at its optimal dilution, fixation being overnight at $4^{\circ} \mathrm{C}$. 


\section{Determination of Rubella-specific IgG and IgM}

Serum fractionation on sucrose density gradients was conducted to detect rubella-specific IgG and IgM (Best et al., 1969). A sample of serum which was known to contain rubella-specific $\operatorname{IgM}$ and $\operatorname{IgG}$ was included as a control with each test.

\section{Isolation of Rubella Virus from Fetal Material}

Ten per cent. suspensions were prepared from ground-up products of conception obtained from patients whose pregnancies were terminated by dilatation and curettage (Green et al., 1965). Similar suspensions were prepared from selected individual organs of fetuses removed by hysterotomy. Rubella virus was identified in RK-13 and patas monkey kidney cultures (Best and Banatvala, 1967).

\section{Results}

\section{Rubella-like Illnesses}

Sera were obtained from 45 patients with rubella-like illnesses during pregnancy. In only $20(44 \%)$ of these did serological studies verify the clinical diagnosis, accurate details about exposure to rubella being available in 16. In most cases, infection was acquired from children, either within the family group (10 cases) or at work-for example, in schools and nurseries (four cases). Considerable delay occurred before many patients came for laboratory investigation, only 16 of the 45 patients $(36 \%$ ) with rubella-like illnesses presenting within a week of the onset of symptoms (Table I). Because haemagglutination-inhibition antibodies develop rapidly, this delay considerably reduced the value of haemagglutination-inhibition tests. Thus, of the serologically confirmed cases five out of seven who presented within a week of onset showed significant rises in antibody titre by haemagglutination-inhibition, but one had a high titre in both sera $(1: 1,024)$. On the other hand, out of 13 patients presenting after this time, only one showed a significant rise in antibody titre. A diagnosis was made in these patients by detecting rises in complement-fixing antibody or by the presence of rubella-specific IgM. Though the presence of high antibody titres-for example, $>1: 512$-in sera of those patients who presented a week or more after the onset of symptoms suggested a recent infection, the converse was not necessarily true, since of the 20 serologically confirmed cases $7(35 \%)$ had antibody titres of $1: 256$ or less in their second serum samples.

Because the number of patients infected with rubella in this series was small, haemagglutination-inhibition antibody titres were compared with those in a series of 77 unselected laboratory-confirmed cases of rubella in the convalescent phase. These sera were obtained from nurses or patients taking part in a general practice survey, and were adsorbed with heparin and manganous chloride before testing. Of these subjects, $44(57 \%)$ had antibody titres of $1: 256$ or less, the geometric mean titre in this series being 1:399 (Table II). These findings emphasize that in the absence of a significant rise in antibody titre an intermediate or low antibody titre by haemagglutination-inhibition during the convalescent phase cannot in itself be regarded as satisfactory evidence that a patient has not been recently infected.

\section{Efficacy of Serological Tests}

The methods by which the diagnosis was made in the 20 serologically confirmed cases of rubella in pregnancy are summarized in Table III. Complement-fixation tests were useful in detecting significant increases in antibody titre when haemagglutination-inhibition antibodies had already reached their maximum levels. Similarly, determination of rubella- specific IgM was particularly useful when either haemagglutination-inhibition or complement-fixation tests on paired sera failed to show a rising titre or when only a single serum sample was available and it was urgently required to know whether the haemagglutination-inhibition antibody had been recently acquired (Table IV). IgM antibody can be consistently detected for only three to four weeks after onset (Best et al., 1969). Thus in the few patients who presented after this time a high antibody titre by haemagglutinationinhibition supported by a high titre by complement-fixation $\left(>_{1: 64)}\right.$ was reasonable circumstantial evidence of recent infection since complement-fixing antibodies-unlike haemagglutination-inhibition antibodies-do not generally persist at a high level for a prolonged period after infection (Field, 1967; Lennette et al., 1967).

TABLE I.-Interval Between Onset of Symptoms and Laboratory Investigation in Patients with Rubella-like Illness

\begin{tabular}{llll|l|l|l|l|l|l|l}
\hline Interval in days & $\therefore$ & $\ldots$ &.. & $1-7$ & $8-14$ & $15-21$ & $22-8$ & $29-35$ & $>36$ \\
No. of patients &. &. &.. & 16 & 9 & 7 & 3 & 5 & 5 \\
\hline
\end{tabular}

TABLE II.-Haemagglutination-inhibition (H.I.) Antibody Titres in Heparin-and-Manganous-Chloride-Absorbed Sera Obtained between 7 and 40 Days After Onset of Symptoms

\begin{tabular}{|c|c|c|c|c|c|c|c|c|c|}
\hline \multirow{2}{*}{$\begin{array}{l}\text { No. } \\
\text { Tested }\end{array}$} & \multirow{2}{*}{$\begin{array}{c}\text { Geometric } \\
\text { Mean } \\
\text { Titre }\end{array}$} & \multicolumn{8}{|c|}{ Reciprocal H.I. Antibody Titre } \\
\hline & & 32 & 64 & 128 & 256 & 512 & $\overline{1,024}$ & $\overline{2,048}$ & 4,096 \\
\hline 77 & 399 & 1(1) & $5(6)$ & $13(17)$ & 25(32) & $15(20)$ & $10(13)$ & $5(6)$ & 3(4) \\
\hline
\end{tabular}

Percentages are given in parentheses.

TABLE III.-Method of Diagnosis in 20 Serologically Confirmed Cases of Maternal Rubella

\begin{tabular}{|c|c|}
\hline Method of Serodiagnosis & No. of Patients Diagnosed \\
\hline 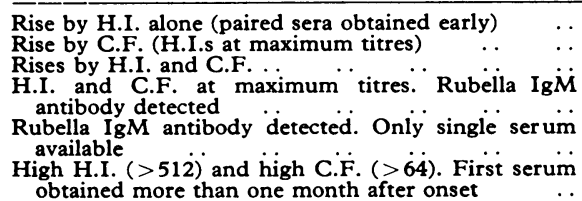 & $\begin{array}{l}5 \\
2 \\
2 \\
6 \\
3 \\
3\end{array}$ \\
\hline
\end{tabular}

TABLE IV.-Serological Details of Patients Exposed to Rubella-like Illnesses in whom Tests to detect Rubella-specific IgM were Conducted

\begin{tabular}{|c|c|c|c|c|c|c|c|c|c|}
\hline & \multirow{2}{*}{\multicolumn{2}{|c|}{$\begin{array}{l}\text { Case } \\
\text { No. }\end{array}$}} & \multicolumn{4}{|c|}{ 1st Serum } & \multicolumn{3}{|c|}{ 2nd Serum } \\
\hline & & & $\begin{array}{l}\text { Days } \\
\text { After } \\
\text { Onset }\end{array}$ & H.I. & C.F. & $\begin{array}{l}\text { Rubella- } \\
\text { specific } \\
\text { IgM }\end{array}$ & $\begin{array}{l}\text { Days } \\
\text { After } \\
\text { Onset }\end{array}$ & H.I. & C.F. \\
\hline $\begin{array}{l}1 \\
2 \\
3 \\
4 \\
5 \\
6 \\
7 \\
8 \\
9\end{array}$ & $\begin{array}{l}\cdots \\
\therefore \\
\cdots \\
\cdots \\
\therefore \\
\therefore \\
\cdots\end{array}$ & $\begin{array}{l}\cdots \\
\cdots \\
\cdots \\
\cdots \\
\cdots \\
\cdots\end{array}$ & $\begin{array}{c}8 \\
10 \\
11 \\
15 \\
23 \\
29 \\
18 \\
22 \\
\text { In apparent } \\
\text { infection }\end{array}$ & $\begin{array}{r}512 \\
128 \\
256 \\
128 \\
1,024 \\
256 \\
256 \\
64 \\
4,096\end{array}$ & $\begin{array}{r}<4 \\
32 \\
64 \\
16 \\
32 \\
64 \\
4 \\
32 \\
>64 \\
\end{array}$ & $\begin{array}{l}+ \\
+ \\
+ \\
+ \\
+ \\
+ \\
+ \\
+ \\
+ \\
+ \\
+\end{array}$ & $\begin{array}{l}15 \\
28 \\
18 \\
26 \\
30 \\
35 \\
\text { N.A. } \\
\text { N.A. } \\
\text { N.A. }\end{array}$ & $\begin{array}{r}1,024 \\
128 \\
256 \\
256 \\
1,024 \\
256 \\
= \\
- \\
-\end{array}$ & $\begin{array}{l}4 \\
32 \\
64 \\
32 \\
32 \\
64 \\
- \\
\\
\end{array}$ \\
\hline $\begin{array}{l}10 \\
11 \\
12 \\
13 \\
14\end{array}$ & $\begin{array}{l}. \\
\cdots \\
\because \\
\therefore\end{array}$ & $\begin{array}{l}\ldots \\
\cdots \\
\cdots \\
\cdots\end{array}$ & $\begin{array}{r}1 \\
8 \\
12 \\
14 \\
16\end{array}$ & $\begin{array}{r}128 \\
64 \\
128 \\
64 \\
64\end{array}$ & $\begin{array}{r}16 \\
16 \\
32 \\
8 \\
16\end{array}$ & $\begin{array}{l}\bar{z} \\
\bar{z}\end{array}$ & $\begin{array}{r}14 \\
14 \\
24 \\
\text { N.A. } \\
\text { N.A. }\end{array}$ & $\begin{array}{r}128 \\
64 \\
128 \\
- \\
-\end{array}$ & $\begin{array}{l}16 \\
16 \\
32 \\
-\end{array}$ \\
\hline
\end{tabular}

* IgM detected before second serum specimen was taken.

N.A. = Not available. TABLE V.-Outcome of Pregnancy in Laboratory-confirmed Cases of

\begin{tabular}{|c|c|c|c|c|}
\hline \multicolumn{3}{|c|}{ Outcome of Pregnancy } & \multirow{2}{*}{$\begin{array}{c}\text { No. Cases } \\
2 \\
2 \\
1 \\
15 \\
10 \\
7\end{array}$} & \multirow{2}{*}{$\begin{array}{c}\begin{array}{c}\text { Duration of Pregnancy } \\
\text { (Weeks) when Infected }\end{array} \\
7,10 \\
9,19 \\
12\end{array}$} \\
\hline $\begin{array}{l}\text { Spontaneous abortion } \\
\text { Pregnancy continuing } \\
\text { Healthy infant delivered } \\
\text { Therapeutic abortions } \\
\text { Specimens received } \\
\text { Rubella virus isolated }\end{array}$ & $\begin{array}{l}\cdots \\
\because \\
\cdots \\
\cdots\end{array}$ & $\begin{array}{l}\ldots \\
\cdots \\
\cdots \\
\cdots \\
\ldots\end{array}$ & & \\
\hline
\end{tabular}




\section{Outcome of Pregnancies}

Of the serologically confirmed cases of rubella (Table V) two had spontaneous abortions and 15 therapeutic abortions. The products of conception from 10 patients were examined virologically and rubella virus was isolated from seven $(70 \%)$. Though they were not investigated virologically, all infants so far delivered at St. Thomas's Hospital to mothers whose illness was shown not to be rubella were healthy at birth.

\section{Patients Exposed to Rubella}

Out of 172 patients exposed to rubella-like illnesses only 17 $(10 \%)$ were seronegative by haemagglutination-inhibition and therefore at risk. Only two of these however were exposed to an index case within their family, and both subsequently developed rubella, one subclinically. In a further instance, both the patient and the index case-her own child-might have been infected by a common source, the patient having a subclinical infection. Serum was obtained from this patient only two days after symptoms had appeared in the child, but both haemagglutination-inhibition and complement-fixing antibody titres in this patient were already high and rubella-specific IgM was present (Table IV, Case 9).

Of the 48 patients exposed to their own children at home and 15 to a child at work, serological studies were conducted on 20 of the 48 home contacts, only nine being shown to have had rubella. In those seropositive patients exposed to laboratory-confirmed cases there were no "booster" responses by either haemagglutination-inhibition or complement-fixation tests to suggest that reinfection had occurred. Of the 172 patients $105(61 \%)$ presented within the first two weeks after exposure (Table VI), $76(44 \%)$ within the first week. Haemagglutination-inhibition antibodies were therefore valuable in determining whether these patients were already immune, since they presented well within the incubation period of rubella. The remaining 67 patients $(39 \%)$ presented more than two weeks after exposure. In these patients it was necessary to do both haemagglutination-inhibition and complementfixation tests on paired sera to determine whether rising antibody titres were obtained. In seven cases haemagglutination-inhibition and complement-fixing antibody titres did not give a clear indication whether the patient had been recently infected, but the absence of rubella-specific IgM suggested that the antibodies were not of recent duration.

TABLE VI.-Interval Between First Exposure to an Index Case and Laboratory Investigation

\begin{tabular}{llll|l|l|l|l|l|l} 
Interval in days &. & $\ldots$ &. & $1-7$ & $8-14$ & $15-21$ & $22-8$ & $29-35$ & 736 \\
No. of patients &. &.. &. & 76 & 29 & 18 & 6 & 8 & 35 \\
\hline
\end{tabular}

Though haemagglutination-inhibition tests showed that most patients were already immune when exposed to rubella-like illnesses, there was considerable variation in their haemagglutination-inhibition antibody titres according to whether sera had been adsorbed with kaolin or with heparin and manganous chloride (Table VII). Those pretreated with kaolin had a geo- metric mean titre of $1: 121,11 \%$ having antibody titres of $1: 512$ or more. In contrast, those pretreated with heparin and manganous chloride had a geometric mean titre of $1: 47$, all having titres of $1: 256$ or less. The presence of occasional high antibody titres following adsorption of sera with kaolin, even though the patient had only recently been exposed to rubella, was often disturbing in case it resulted from a recent infection. For this reason sera from such patients were occasionally referred by other laboratories for density gradient studies. When these sera were retested by haemagglutination-inhibition after pretreatment with heparin and manganous chloride, much lower antibody titres were generally found. Furthermore, undetectable or low levels of complement-fixing antibody and the absence of rubella-specific IgM confirmed that these high haemagglutination-inhibition antibody titres in the kaolinadsorbed sera were not due to a recently acquired infection.

\section{Discussion}

Understandably, there is considerable anxiety that exposure to a rubella-like illness during pregnancy may result in the development of congenital abnormalities. In our study, however, only $10 \%$ of patients exposed to a rubella-like illness were seronegative; just under half of the index cases to whom patients were exposed and a similar proportion of pregnant women with rubella-like illnesses were accurately diagnosed clinically. Most of those who contracted rubella were exposed closely over a prolonged period, usually at home. On the other hand those who were seronegative and exposed to nonfamily contacts, even though this had sometimes been over a two- to three-hour period, did not become infected. Other surveys have shown that the proportion of seronegative women of child-bearing age varies between roughly 5 and $20 \%$ (Rawls et al., 1967; P.H.L.S., 1968a), these figures being related to such factors as socio-economic status and population density. Though the number of seronegative patients in our series was small, another survey has also confirmed that the risk of contracting rubella from a proved index case in the same household is high, being five times more likely than when contact was outside the household (P.H.L.S., 1968a).

Though ideally a decision to terminate pregnancy should be based on more than one serological test (Rawls et al., 1968) this was seldom possible in our series because many patients presented after the acute phase of their illness. In experienced hands the haemagglutination-inhibition test is extremely reliable and provides a rapid result, but unfortunately delay in patients seeking advice placed considerable reliance on other tests. Thus, though a significant rise in antibody titre by haemagglutination-inhibition may generally be obtained within a week, provided patients present within 48 hours of onset of symptoms (Banatvala and Hudson, unpublished observations); after this time antibodies seldom rise further. In general, most practitioners referred patients promptly to obstetric departments or even direct to the laboratory. Some patients, however, did not consult their general practitioners about their illness until a considerable time had elapsed, or failed to inform them altogether, admitting to their illness only when questioned about their general health during a subsequent routine antenatal visit.

TABLE VII.-Range of Titres in Sera of Patients with Pre-existing Antibody Following Serum Adsorption with Kaolin ( $f u l y$ 1966 to fanuary 1968) or Heparin and Manganous Chloride (February 1969 to February 1970)

\begin{tabular}{|c|c|c|c|c|c|c|c|c|c|c|c|c|c|c|c|c|c|}
\hline \multicolumn{6}{|c|}{ Serum Adsorption } & \multirow[t]{2}{*}{ No. Tested } & \multirow{2}{*}{$\begin{array}{l}\text { Geometric } \\
\text { Mean Titre }\end{array}$} & \multicolumn{10}{|c|}{ Reciprocal H.I. Antibody Titre } \\
\hline & & & & & & & & 8 & 16 & 32 & 64 & 128 & 256 & 512 & 1,024 & 2,048 & 4,096 \\
\hline $\begin{array}{l}\text { Kaolin } \\
\text { Hep./MnCl}\end{array}$ & $\cdots$ & $\ldots$ & 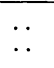 & $\therefore$ & $\begin{array}{l}\ldots \\
.\end{array}$ & $\begin{array}{l}92 \\
60\end{array}$ & $\begin{array}{r}121 \\
47\end{array}$ & $\begin{array}{l}1 \text { (1) } \\
4 \text { (6) }\end{array}$ & $\begin{array}{r}1(1) \\
11(18)\end{array}$ & $\begin{array}{l}15(16) \\
15(25)\end{array}$ & $\begin{array}{l}18(20) \\
12(20)\end{array}$ & $\begin{array}{l}25(27) \\
13(22)\end{array}$ & $\begin{array}{l}22(24) \\
5(8)\end{array}$ & $\begin{array}{l}6(7) \\
0(0)\end{array}$ & $\begin{array}{l}3(3) \\
0(0)\end{array}$ & $\begin{array}{l}1(1) \\
0(0)\end{array}$ & $\begin{array}{l}O(0) \\
O(0)\end{array}$ \\
\hline
\end{tabular}

Percentages are given in parentheses 
Though certain workers tend to place some diagnostic value on the level of haemagglutination-inhibition antibody titres, the occasional low antibody titres found during the convalescent phase makes this a dangerous practice. Higher antibody titres were more often obtained when sera were adsorbed with kaolin, but this method was eventually discarded since occasional extremely high antibody titres were found in patients who had not been recently infected. Furthermore, kaolin sometimes fails to remove non-specific inhibitors satisfactorily, thereby giving rise to random and unpredictable false-positive results (Feldman, 1968; Cabasso et al., 1969).

Because complement-fixing antibody titres rise later than haemagglutination-inhibition antibody titres (Field, 1967; Lennette et al., 1967; Sever et al., 1967), complement-fixation tests were useful in detecting rising titres when haemagglutination-inhibition titres had reached their maximum levels. The complement-fixation test however is probably somewhat less reliable diagnostically than the haemagglutination-inhibition test. We have found considerable variation in the complementfixing antibody response among laboratory-confirmed cases of rubella, probably due to the potency of different batches of antigen. Determination of rubella-specific $\operatorname{IgM}$ was useful, therefore, in confirming the diagnosis when either haemagglutination-inhibition or complement-fixing antibody titres did not rise significantly or when only a single serum was available. The relatively high proportion of sera tested by this method reflected the fact that sera from a number of patients whose serological results were difficult to interpret were referred from other laboratories, for of 21 tests carried out only five were on patients at St. Thomas's or other hospitals within the group.

Those patients who presented more than a month after onset were difficult to evaluate, for though a high antibody titre by both haemagglutination-inhibition and complement-fixation provided reasonable circumstantial evidence that infection by rubella had occurred, no clear direction could be given in the absence of such findings. A decision on whether to terminate pregnancy had therefore to be made by the obstetrician on clinical grounds alone. There is some controversy over the prophylactic value of $\gamma$-globulin and it was not given to patients in our series. Its administration is, however, extremely unlikely to affect the interpretation of serological tests, since no haemagglutinationinhibition antibody can be detected following the administration of $750 \mathrm{mg}$., and only extremely low titres appeared after the administration of 3,000 mg. (P.H.L.S., 1968b).

It is quite likely that most of the patients who had rubella would have had therapeutic abortions even if laboratory tests were unavailable. A number of pregnancies, however, were saved because the clinical diagnosis of maternal rubella was shown to be incorrect. Furthermore, considerable anxiety was allayed by reassuring many patients exposed to rubella that they were either immune or that the diagnosis in the index case was incorrect. Nevertheless, during the period of these investigations eight infants with laboratory-confirmed congenitally acquired rubella were born at St. Thomas's Hospital. In most of these cases maternal infection was either subclinical or atypical and was not investigated serologically, since no history of illness or even exposure to rubella had been obtained. Six of these infants, however, were born to coloured immigrant mothers, among whom the rash may often be difficult to detect.

It is hoped that eventually attenuated rubella virus vaccines, which have just been licensed in Great Britain (British Medical fournal, 1970), may considerably reduce the incidence of rubella-caused congenital deformities. Meanwhile, both patients and their doctors must be encouraged to report exposure to rubella or rubella-like illnesses in pregnancy as early as possible, so that laboratory investigations may be conducted with minimum delay.

We are indebted to many for their co-operation: the obstetrical staff of St. Thomas's and the Lambeth Hospitals, particularly Sister Munro; Professor J. C. McClure Browne, Royal Postgraduate Medical School; Professor K. R. Dumbell, St. Mary's Hospital Medical School; Dr. J. A. Dudgeon, Hospital for Sick Children, Great Ormond Street; Dr. J. R. Davies, P.H.L.S., County Hall; Dr. C. Dulake, P.H.L.S., Guildford; Dr. D. R. Gamble, P.H.L.S., Epsom; Dr. J. V. T. Gostling, P.H.L.S., Portsmouth; and Dr. G. H. Tee, P.H.L.S., Dorchester.

This work was supported by a grant from the Medical Research Council.

\section{REFERENCES}

Best, J. M., and Banatvala, J. E. (1967). Fournal of Hygiene, 65, 263 Best, J. M., Banatvala, J. E., and Watson, D. (1969). Lancet, 2, 65. Bradford Hill, A., Doll, R., Galloway, T. M. L., and Hughes, J. P. W. (1958). British fournal of Preventive and Social Medicine, 12, 1. British Medical foumal 1970, 1, 318.

Cabasso, V. J., et al. (1969). Applied Microbiology, 18, 410.

Cooper, L. Z., Matters, B., Rosenblum, J. K., and Krugman, S. (1969). Fournal of the American Medical Association, 207, 89.

Feldman, H. A. (1968). Proceedings of the Society for Experimental Biology and Medicine, 127, 570.

Field, A. (1967). Fournal of Hygiene, 65, 409.

Green, R. H., Balsamo, M. R., Giles, J. P., Krugman, S., and Mirick, G. S. (1965). American fournal of Diseases of Children, 110, 348.

Halonen, P. E., Ryan, J. M., and Stewart, J. A. (1967). Proceedings of the Society for Experimental Biology and Medicine, 125, 162

Hill, A. B., Doll, R., Galloway, T. McL., and Hughes, J. P. W. (1958). British fournal of Preventive and Social Medicine, 12, 1.

Lennette, E. H., Schmidt, N. J., and Magoffin, R. L. (1967). Fournal of Immunology, 99, 785 .

Lundström, R. (1952). Acta Paediatrica, 41, 583.

Lundström, R. (1962). Acta Paediatrica, 51, Suppl. No. 133.

Manson, M. M., Logan, W. P. D., and Loy, R. M. (1960). Rubella and Other Virus Infections during Pregnancy. London H.M.S.O.

Pitt, D., and Keir, E. H. (1965). Medical fournal of Australia, 2, 647, $691,737$.

Plotkin, S. A., Bechtel, D. J., and Sedwick, W. D. (1968). American fournal of Epidemiology, 88, 301.

Public Health Laboratory Service (1968a). British Medical fournal, 3, 203.

Public Health Laboratory Service (1968b). British Medical fournal, 3, 206.

Rawls, W. E., Desmyter, J., and Melnick, J. L. (1968). Fournal of the American Medical Association, 203, 627.

Rawls, W. E., et al. (1967). Bulletin of the World Health Organization, 37, 79.

Sever, J. L., et al. (1967). Pediatrics, 40, 789

Sheridan, M. D (1964). British Medical fournal, 2, 536.

Stewart, G. L., et al. (1967). New England fournal of Medicine, 276, 554 . 